Ger J Exerc Sport Res 2022 · 52:119-124 https://doi.org/10.1007/s12662-021-00747-1 Received: 27 April 2021

Accepted: 3 August 2021

(c) Springer-Verlag GmbH Deutschland, ein Teil von Springer Nature 2021

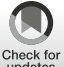

Published online: 6 September 2021

\author{
Bahar Hassanmirzaei ${ }^{1,2,5}$ (D) Z Zohreh Haratian² $\cdot$ Ali Ahmadzadeh Amiri ${ }^{1}$ \\ Mahdi Alinejad ${ }^{3} \cdot$ Gurcharan Singh $^{4}$ \\ 'Sports Medicine Research Center, Neuroscience Institute, Tehran University of Medical Sciences, Tehran, \\ Iran \\ ${ }^{2}$ Iran Football Medical Assessment and Rehabilitation Center, IFMARC, FIFA Medical Centre of Excellence, \\ Tehran, Iran \\ ${ }^{3}$ Deputy Minister of Sports and Youth, Tehran, Iran \\ ${ }^{4}$ AFC Medical Committee, Kuala Lumpur, Malaysia \\ ${ }^{5}$ Tehran, Iran
}

\section{Resumption of professional football during the COVID-19 pandemic. Study findings from Iran}

\section{Introduction}

Since the beginning of 2020, the world has been plagued by coronavirus disease 2019 (COVID-19). This infection is caused by the severe acute respiratory syndrome coronavirus type 2 (SARS$\mathrm{CoV}-2$ ) and causes a wide range of symptoms, from mild respiratory symptoms to severe illness and even death (Grant et al., 2020). As the virus has been spreading rapidly, the WHO (World Health Organization) has declared COVID-19 a pandemic since 11 March 2020 (World Health Organization, 2020; Cascella, Rajnik, Aleem, Dulebohn, \& Di Napoli, 2021).

This pandemic did not leave the world of football untouched as many countries' health authorities and governments applied limitations to reduce the virus's propagation rate (Corsini, Bisciotti, Eirale, \& Volpi, 2020). As a re-

\footnotetext{
Availability of data and material

The data of players' and officials' COVID-19 tests in this study are available from Iran Football Medical Assessment and Rehabilitation Center (IFMARC) and Iran Football League Organization. But restrictions apply to the availability of these data, which were used under license for the current study, and so are not publicly available.

Code availability

Not Applicable
}

sult, football matches and training were suspended until a method of decreasing infection risk was established (HerreroGonzalez et al., 2020; Meyer et al., 2021; Wilson et al., 2020).

The Iran CORONA Headquarter in sport suspended Iranian professional men's football premier league (Persian GulfPro League) and Knockout Cup (Iranian Hazfi Cup) 2019/2020 season on 29 February 2020, due to the COVID19 outbreak. Although the desire to restart the competitions as soon as possible was surging among players, clubs, and even the fans, the biggest challenge facing the federation and the league was to find suitable safety precautions that protect the health of players, staff, and officials. Therefore, based on the rules and recommendations of the ministry of health, CORONA headquarter in sports formally decided to evaluate the restart of the season under particular restrictions and declared the regulation of football league matches during the corona pandemic in Iran.

This is a report to describe the status of the professional football setting regarding COVID-19 over a modified football season resumption under particular regulations at the peak of the pandemic in a country with high transmission risk. These findings may shed light on how to resume the sports events during the pandemic.

\section{Methods}

Study design

This prospective cohort study was conducted between 17 May 2020, and 3 September 2020, and included 16 Iranian professional men's premier league teams and the match officials. The timeline of the professional restart can be found in - Fig. 1.

\section{Ethical considerations}

This study was performed according to the principles of the Declaration of Helsinki. The protocol was approved by the ministry of health and Iranian Football Medical Assessment and Rehabilitation Center (IFMARC) Ethical Committee and Iran Football League Organization. Also, IFMARC was responsible for the supervising the resumption. On behalf of their players and officials, all teams' boards formally agreed to cooperate in this study. 


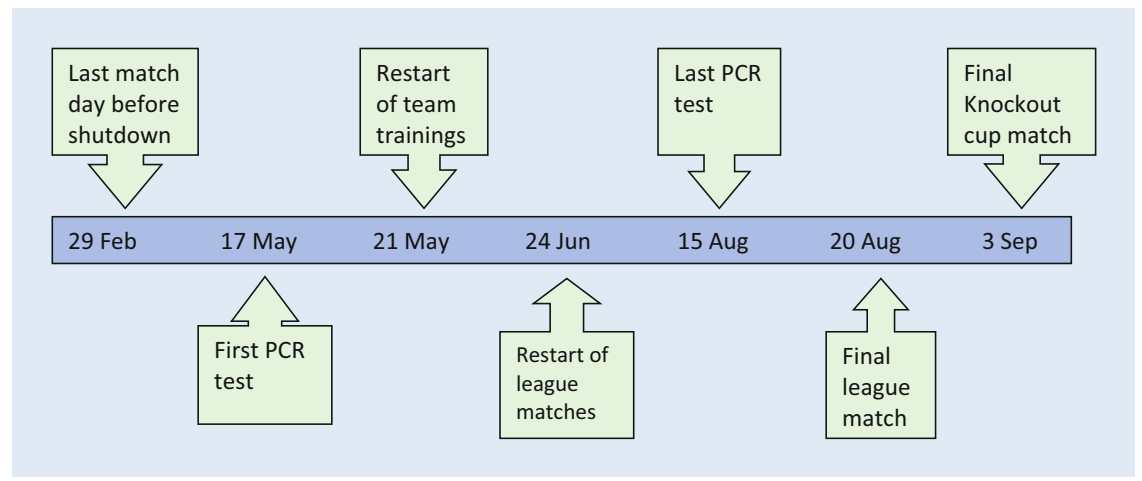

Fig. $1 \Delta$ Time schedule for the Iranian professional football competitions from the COVID-19 shutdown to its final match after restart

\section{Restricted hygiene measures}

The measures consist of case identification, regular and repetitive COVID19 PCR testing, a self-reported symptom checker, positive case isolation, and determining the COVID-19 infection prevalence while holding the football premier league. According to the regulations of the CORONA headquarters in sports, if more than $25 \%$ of the team members were found to have positive PCR tests while more than $80 \%$ of them were players, the upcoming match has to be canceled. It should be postponed until the team members' positive PCR test falls below this set point.

\section{Symptom monitoring}

Symptoms were monitored using a selfdeclaration form provided for the players, staff, and officials. The document was created based on the official reports of the Iran Ministry of Health, Research, and Education and Iran CORONA headquarter based on commonly reported symptoms of COVID-19. Before the restart, the common symptoms of COVID-19 were thoroughly explained to the players, staff, and officials by the medical team. They were asked to report any illness or suspicious symptoms to the team physicians immediately by an online selfdeclaration form.

\section{PCR testing}

All the players provided pharyngeal swabs for SARS-CoV-2 RNA PCR testing for the first time on 17 May 2020. The tests were supposed to be performed every 5 days based on the first regulation. However, the frequency was reduced to every 10 days by the CORONA headquarter in sports to make it more feasible for teams to follow. Samples were analyzed in laboratories and by PCR kits authorized by the Iran Ministry of Health, Research, and Education. We used the Sansure SARS-CoV-2 RTPCR kit (Hunan, China; target genes: ORF1ab/N) and the reporting followed manufacturer instructions.

\section{Case monitoring and tracing}

Individuals with suspicious symptoms or exposure to a COVID-19 patient were tested for the virus and underwent selfisolation with close symptom monitoring. Those with a positive test stayed in self-isolation until $48 \mathrm{~h}$ after the disappearance of all the symptoms and asymptomatic cases could return to play after a negative PCR test. In case of a positive case, all team physicians performed the case-tracing interview, and immediately after, tests were performed on the previous opposition team in order to identify the index case. Furthermore, team physicians were suggested to follow the practical guideline on cardiorespiratory considerations for return to sports in elite athletes. The final PCR test was performed on 15 August 2020, and both league matches and Knockout Cup successfully finished on 20 August 2020 and 3 September 2020, respectively.

\section{Statistics}

SPSS (License: Trialware SaaS) software version 22.0 was used to report analytic and descriptive statistics. Raw numbers and percentages were used to illustrate the outcomes of our study.

\section{Results}

\section{Competitions}

The Iranian professional men's football premier league (Persian Gulf Pro League) and Knockout Cup (Iranian Hazfi Cup) 2019/2020 season both finished successfully within the scheduled period (77 matches). The total duration was 110 days (23 match days). The final matches took place on 20 August 2020 and 3 September 2020, respectively, and a total of $7156 \mathrm{~min}$ of the match was performed during this duration. Due to the resource limitations and the expensive PCR tests, the two remaining teams for the cup final did not agree to take part in the last round of PCR testing. They alternatively isolated their team members $48 \mathrm{~h}$ before the match and excluded the symptomatic individuals.

All 16 league teams enrolled in this study. A total of 805 individuals consisting of 459 players and 346 staff members and officials participated and were tested regularly. The competitions were held in a total period of redesigned 14 assigned match weeks, where each week was designed to be 4-7 days in length to shorten the whole duration of remained league weeks, plus 38 days of training. The total number of days and matches allocated for each week and the total number of performed PCR tests, and the number of positive PCR tests for each week are summarized in - Table 1. Fortunately, no severe courses of the disease were reported, and no individual needed to be hospitalized. On 4 July 2020, the PCR results of more than $25 \%$ of the members of two teams returned positive; therefore, two matches were postponed. Since all those cases were asymptomatic, according to the protocol, after 10 days and two negative PCR tests, the matches were rescheduled to be held. 


\section{Symptoms}

While all the team players and officials were educated and informed about the importance of daily filling of the COVID19 self-declaration form, no suspicious symptoms were reported by any individual through the self-declaration form before the tests. After a positive test, they were obligated to self-quarantine separately in their own homes. Only $22.22 \%$ of the infected subjects (32 out of 144) reported the experience of mild to moderated symptoms in the following days during their quarantine.

\section{PCR tests}

A total of 4066 tests were performed, which is summarized in - Table 2. According to Table 3, a sum of 191 positive tests were detected throughout the whole resumption. Overall, $17.89 \%$ of our population (144 out of 805 individuals) were infected with the SARS-CoV-2 virus. Eighty-five players ( $18.52 \%$ of players) and 59 staff and officials $(17.05 \%$ of staff and officials) were infected during this period. The difference between the infected proportion in the two categories was not statistically significant $(P=0.59)$.

\section{Case tracing}

Our contact tracing revealed that 21 (14.6\%) individuals were infected in contact with a positive case in a football setting (•Table 4). After interviewing the infected subjects, team physicians manifested that of 85 infected players, $11(12.94 \%)$ reported to have been in contact with a fellow teammate with a positive PCR test in a football setting either in a training session and off the pitch or in an official match. Also, $87.5 \%$ of the team's medical staff, who had a positive PCR test, reported close contact inside their team.

\section{Discussion}

\section{Principal findings}

In this study, we reported the status of the professional football restart regarding COVID-19 under national regula- tions during the pandemic. Under hygienic precautions, 805 individuals from 16 teams participated in 77 matches. During that time, no severe course of disease which required hospitalization or critical medical care has been detected. However, 191 individuals (17.89\%) were infected with the coronavirus (diagnosed with a positive PCR test). Furthermore, in our study, no suspicious symptoms were reported by the team physicians or the participants before the tests. Thus, symptom monitoring alone seemed to be ineffective in precisely indicating the disease's status (Gostic, Gomez, Mummah, Kucharski, \& Lloyd-Smith, 2020), especially in our young athletic population who are less likely to express significant symptoms compared to the general population (Baettig, Parini, Cardona, \& Morand, 2021; Williamson, Walker, \& Bhaskaran, 2020). Undeniably, we tried to emphasize on early case identification as the most practical method in controlling the disease's spread (Peck, 2020; Poon et al., 2003), mainly when more asymptomatic cases in the population are expected. Therefore, repeated regular PCR testing played a pivotal role in our approach to resume the sports event (Loeffelholz \& Tang, 2020; WHO Novel Coronavirus (2019-nCoV) technical guidance, 2020).

\section{Why higher rates of infection?}

Compared to the studies conducted by Meyer et al. (2021) and Schumacher, Tabben, and Hassoun (2020), which reported the status of Germany and Qatar professional football resumption, respectively, our infectious rate was relatively higher. Although it is difficult to express whether football resumption is associated with an increased rate of COVID19 infection, it is worthy to remark that in Iran, the population infectious rate during our study period was 20 cases per 100,000 per week (Roser, Ritchie, OrtizOspina, \& Hasell, 2020), compared to only 5 per 100,000 infections per week in Germany (Meyer et al., 2021). Thus, the nation-wide rate may might justify our higher infectious rates. On the other hand, various other factors could be associated with a higher infectious rate in
Ger J Exerc Sport Res 2022 · 52:119-124 https://doi.org/10.1007/s12662-021-00747-1 (c) Springer-Verlag GmbH Deutschland, ein Teil von Springer Nature 2021

B. Hassanmirzaei · Z. Haratian ·

A. Ahmadzadeh Amiri · M. Alinejad. G. Singh

Resumption of professional football during the COVID-19 pandemic. Study findings from Iran

\section{Abstract}

Due to concerns of severe acute respiratory syndrome coronavirus type 2 (SARS-CoV-2) transmission, professional football (soccer) was terminated almost everywhere in the world in early 2020 . These are the results from a prospective cohort study conducted in Iran to analyze the resumption of professional football during the coronavirus disease 2019 (COVID-19) pandemic under assigned protocols and regulations. Sixteen teams consisting of 805 individuals formally agreed to follow the rules assigned by the ministry of health and CORONA headquarters in sport, and were subject to study monitoring. The resumption process was implemented over a 5-month period, beginning with a training phase followed by 14 match weeks of professional football. A self-declaration form was provided for the subjects to report any suspicious symptoms immediately and serial PCR testing was performed every 10 days using nasal swab samples. Those with positive tests were to be isolated until the symptoms were resolved or a negative test was returned. Of the 805 individuals included, $17.89 \%$ subjects were infected by the SARS-CoV-2 virus ( 85 players and 59 staff members and officials). Only two matches were canceled in accordance with the regulations, and no severe cases were found. Case-tracing suggested that most transmissions occurred off the pitch. In conclusion, applying strict hygiene protocols and early case identification by performing repetitive PCR testing could benefit the resumption of professional football competitions.

Keywords

SARS-CoV-2 $\cdot$ Sports $\cdot$ Polymerase chain reaction $\cdot$ Soccer $\cdot$ Virus 


\begin{tabular}{|c|c|c|c|c|}
\hline Periods & Days & Matches (n) & Performed PCR tests & Positive tests (\%) \\
\hline Training & 38 & 0 & 1596 & $72(4.51)$ \\
\hline MW1 & 4 & 1 & 254 & $6(2.36)$ \\
\hline MW2 & 6 & 8 & 414 & $34(8.21)$ \\
\hline MW3 & 6 & 6 & 408 & $24(5.88)$ \\
\hline MW4 & 6 & 7 & 317 & $20(6.30)$ \\
\hline MW5 & 7 & 8 & 434 & $20(4.60)$ \\
\hline MW6 & 4 & 8 & 55 & $0(0)$ \\
\hline MW7 & 4 & 2 & 192 & $7(3.64)$ \\
\hline MW8 & 6 & 8 & 114 & $2(1.75)$ \\
\hline MW9 & 4 & 4 & 5 & $3(60.0)$ \\
\hline MW10 & 5 & 6 & 248 & $3(1.20)$ \\
\hline MW11 & 5 & 8 & 29 & $0(0)$ \\
\hline MW12 & 5 & 8 & 0 & $0(0)$ \\
\hline MW13 & 9 & 2 & 0 & $0(0)$ \\
\hline$M W 14^{a}$ & 1 & 1 & 0 & $0(0)$ \\
\hline Total & 110 & 77 & 4066 & $191(4.69)$ \\
\hline
\end{tabular}

Table 2 Number of performed PCR tests in players and staff

\begin{tabular}{|l|l|l|l|l}
\hline Groups & Tests & Tests per person & Tests per match & Tests per day \\
\hline Players & 2503 & 5.45 & 32.51 & 22.75 \\
\hline Staff and officials & 1563 & 4.51 & 20.29 & 14.21 \\
\hline Total & 4066 & 5.05 & 52.80 & 36.96
\end{tabular}

Table 3 Number of positive PCR tests in players and staff

\begin{tabular}{|l|l|l|l}
\hline Groups & Positive PCR & Positive PCR per match & Positive PCR per day \\
\hline Players & $116(4.63 \%)$ & 1.51 & 1.05 \\
\hline Staff and officials & $75(4.80 \%)$ & 0.97 & 0.68 \\
\hline Total & $191(4.69 \%)$ & 2.48 & 1.73
\end{tabular}

Table 4 Contact tracing of the individuals with positive PCRtests

\begin{tabular}{|c|c|c|c|}
\hline Area of contact & $\begin{array}{l}\text { Players } \\
n=85, n(\%)\end{array}$ & $\begin{array}{l}\text { Officials and staff } \\
n=51, n(\%)\end{array}$ & $\begin{array}{l}\text { Medical staff } \\
n=8, n(\%)\end{array}$ \\
\hline Undefined (unknown) & $23(27.05)$ & $21(41.17)$ & $0(0)$ \\
\hline $\begin{array}{l}\text { Contact with a positive case among } \\
\text { family members }\end{array}$ & $18(21.17)$ & $12(23.59)$ & $0(0)$ \\
\hline $\begin{array}{l}\text { Attending outdoor gatherings/ } \\
\text { celebrations or restaurants }\end{array}$ & $32(37.64)$ & $15(29.41)$ & $0(0)$ \\
\hline Attending a health care facility & $1(1.17)$ & $0(0)$ & $1(12.5)$ \\
\hline $\begin{array}{l}\text { Contact with a positive case from } \\
\text { football setting }\end{array}$ & $11(12.94)$ & $3(5.88)$ & $7(87.5)$ \\
\hline
\end{tabular}

Iran, such as the economic and social barriers of establishing an isolated and centralized camp during the competition, uncontrolled and frequent commuting of participants in the community during the competition, and the attitudes of players as individuals with high physical strength towards the COVID-19.
Even though it is deceivable to interpret that our measures can be applied thoroughly for other settings, we reported a positive rate of $4.69 \%$ in our setting while, during the same period, the positive rate was $10.35 \%$ of the tested individuals in the country (Walsh et al., 2020). Although we managed to finish the season with approximately 1.31 cases per day and no severe cases, it is notable that due to the involvement of multiple factors such as the public's uncertain attitude towards the pandemic, our study design is unable to illuminate how this would affect our population.

\section{PCR testing limitations}

The pragmatic challenge of our study was to rely solely on the results of the PCR tests to make decisions for the individuals or the teams. Aside from its considerable costs, the PCR test cannot precisely distinguish between past and current viral infection. A positive PCR test, especially in asymptomatic individuals, can typically be due to contiguous remnants of the virus in the pharynx (Walsh et al., 2020; Gao et al., 2021). Also, since no COVID-19 testing has been performed on our subjects before this study, there is the possibility to detect an old infection in those who tested positive for the first time.

On the other hand, although PCR is a sensitive test, if the virus colonizes in lower respiratory tract regions or the sample-taking technique is not performed correctly, it would come up as a false negative (Yan, Chang, \& Wang, 2020; Wölfel et al., 2020; Winichakoon et al., 2020). The sample-taking is an unpleasant experience for each individual, and teams tend to keep their valuable players for the season's final stages. Hence, we used external laboratory testing staff to minimize these possible behaviors.

\section{COVID-19 transmission and football}

Although during the case-tracing interviews, most subjects found it difficult to distinguish the precise location of transmission, there has been no report of transmissions between two different teams on the pitch. Our more in-depth assessments let us to assume that the virus transmission is more likely to happen between teammates in shared hotel rooms or the locker rooms rather than on the pitch. Trying to support this statement, after finding a positive PCR test, we immediately performed the tests on the 
previous opposition team and the results unveiled no positive tests. Our findings are in line with the results of the study by Jones, Phillips, and Kemp (2021), who concluded that despite of a high number of close interactions between players during a rugby match, in-game SARSCoV-2 transmission is limited during outdoor sport competitions. While focusing solely on the player interactions is probably an oversimplification of SARSCoV-2 transmission, these results could indicate that taking more strict measures off the pitch is possibly more profound than the match itself. Furthermore, our results showed that since team doctors and physiotherapists spend a longer duration of stay with players providing them with the medical and rehabilitation services, more emphasis must be placed on protective measures for the medical staff.

\section{Study limitations}

It is notable to acknowledge our study's limitations. To elaborate, not all teams could follow the regulation due to the testing cost. Therefore, a different timeline of testing was reported by each team, additionally, owing to the price of the PCR tests, the lack of testing external staff in the pandemic, and the inconvenience of the sampling process for the individuals, we could not perform tests on a shorter duration basis, which would be the most desirable circumstance for our study. We believe that using a sample pooling strategy (Lagopati et al., 2021) could reduce the costs of the tests and improve the effectiveness of case detection, therefore further studies are needed using this method to evaluate the hypothesis. Since reporting CT values for RT-PCR and performing immunity profiling were not obligatory according to the CORONA headquarter protocols, we could not assess these measures in our study. Besides, the self-declaration form was supposed to be filled by the individuals after enough education was provided to them by the medical team. However, to place reliance on unsupervised individuals to report symptoms of a viral disease to be quite vague is another limitation of our study.

\section{Conclusion}

This report of the resumption of professional football after the COVID-19 pandemic under the assigned protocols of Iranian CORONA headquarters in sport revealed that in a situation-where due to financial constraints it was not feasible to set up isolated sport camps (bubbles) for the competitions-repetitive PCR testing alongside symptom monitoring and casetracing made restarting outdoor sporting events possible. We showed that more attention should be paid to prevent the spread of the virus off the pitch compared to in-match contacts. Using shorter timeframes in testing or using pool sampling methods may be beneficial. Having relied on self-reported symptom monitoring may have had its limitations in the presented model.

\section{Corresponding address}

Bahar Hassanmirzaei, MD
14395-578, No. 7, Al-e-
Ahmad Highway, Tehran, Iran
bahariane@yahoo.com

Acknowledgements. We would like to thank all Iranian professional football clubs and their members, especially their medical teams, who fully contributed, followed the resumption guidelines completely and supported this study cooperatively. In addition, we were very thankful for all the laboratories that performed the PCR test for clubs in the various Iran cities.

Author Contribution. Study design: $\mathrm{BH}, \mathrm{ZH}, \mathrm{MA}$, and GS. Data collection and analysis: $\mathrm{BH}, \mathrm{ZH}$, and $\mathrm{AA}$. Writing and proofreading of the manuscript: $\mathrm{BH}, \mathrm{ZH}$, $A A, M A$, and GS.

\section{Declarations}

Conflict of interest. B. Hassanmirzaei, Z. Haratian, A. Ahmadzadeh Amiri, M. Alinejad and G. Singh declare that they have no competing interests.

All procedures performed in studies involving human participants or on human tissue were in accordance with the ethical standards of the institutional and/or national research committee and with the 1975 Helsinki declaration and its later amendments or comparable ethical standards. The protocol was approved by the Ministry of Health and Iran Football Medical Assessment and Rehabilitation Center (IFMARC) Ethical Committee and Iran Football League Organization. Also, IFMARC was responsible for the supervising the resumption. On behalf of their players and officials, all teams' boards formally agreed to cooperate in this study.

\section{References}

Baettig, S. J., Parini, A., Cardona, I., \& Morand, G. B. (2021). Case series of coronavirus (SARS-CoV2) in a military recruit school: clinical, sanitary and logistical implications. BMJ Military Health, 167(4), 251-254. https://doi.org/10.1136/ bmjmilitary-2020-001482.

Cascella, M., Rajnik, M., Aleem, A., Dulebohn, S.C., \& Di Napoli, R. (2021). Features, evaluation, and treatment of Coronavirus (COVID-19). Treasure Island: StatPearls.

Corsini, A., Bisciotti, G. N., Eirale, C., \& Volpi, P. (2020). Football cannot restart soon during the COVID19 emergency! A critical perspective from the Italian experience and a call for action. British Journal of Sports Medicine, 54(20), 1186-1187. https://doi.org/10.1136/bjsports-2020-102306.

Gao, Z., Xu, Y., Sun, C., Wang, X., Guo, Y., Qiu, S., \& Ma, K. (2021). A systematic review of asymptomatic infections with COVID-19. Journal of Microbiology, Immunology, and Infection, 54(1), 12-16. https://doi.org/10.1016/j.jmii. 2020.05.001.

Gostic, K., Gomez, A.C., Mummah, R. O., Kucharski, A. J., \& Lloyd-Smith, J. O. (2020). Estimated effectiveness of symptom and risk screening to prevent the spread of COVID-19. eLife, 9, e55570. https://doi.org/10.7554/eLife.55570.

Grant, M.C., Geoghegan, L., Arbyn, M., Mohammed, Z., McGuinness, L., Clarke, E. L., \& Wade, R.G. (2020). The prevalence of symptoms in 24,410 adults infected by the novel coronavirus (SARSCoV-2; COVID-19): a systematic reviewand metaanalysis of 148 studies from 9 countries. PLOS One, 15(6), e234765. https://doi.org/10.1371/ journal.pone. 0234765 .

Herrero-Gonzalez, H., Martín-Acero, R., Del Coso, J., Lalín-Novoa, C., Pol, R., Martín-Escudero, P., De la Torre, A.I., Hughes, C., Mohr, M., Biosca, F., \& Ramos, R. (2020). Position statement of the Royal Spanish Football Federation for the resumption of football activities after the COVID 19 pandemic (June 2020). British Journal of Sports Medicine, 54(19), 1133-1134. https://doi. org/10.1136/bjsports-2020-102640.

Jones, B., Phillips, G., Kemp, S., et al. (2021). SARS-CoV-2 transmission during rugby league matches: Do players become infected after participating with SARS-CoV-2 positive players? British Journal of Sports Medicine. https://doi.org/10.1136/ bjsports-2020-103714.

Lagopati, N., Tsioli, P., Mourkioti, I., Polyzou, A., Papaspyropoulos, A., Zafiropoulos, A., Evangelou, K., Sourvinos, G., \& Gorgoulis, V.G. (2021). Sample pooling strategies for SARSCoV-2 detection. Journal of Virological Methods, 289, 114044. https://doi.org/10.1016/j.jviromet. 2020.114044 .

Loeffelholz, M.J., \& Tang, Y.W. (2020). Laboratory diagnosis of emerging human coronavirus infections - the state of the art. Emerging Microbes \& Infections, 9(1), 747-756. https://doi. org/10.1080/22221751.2020.1745095.

Meyer, T., Mack, D., Donde, K., Harzer, O., Krutsch, W., Rössler, A., Kimpel, J., von Laer, D., \& Gärtner, B. C. (2021). Successful return to professional men's football (soccer) competition after the COVID- 
19 shutdown: a cohort study in the German Bundesliga. British Journal of Sports Medicine, 55(1), 62-66. https://doi.org/10.1136/bjsports2020-103150.

Peck, K. R. (2020). Early diagnosis and rapid isolation: response to COVID-19 outbreak in Korea. Clinical Microbiology and Infection, 26(7), 805-807. https://doi.org/10.1016/j.cmi.2020.04.025.

Poon, L. L., Chan, K. H., Wong, O. K., Yam, W. C., Yuen, K. Y., Guan, Y., Lo, Y. M., \& Peiris, J. S. (2003). Early diagnosis of SARS coronavirus infection by real time RT-PCR. Journal of Clinical Virology, 28(3), 233-238. https://doi.org/10.1016/j.jcv.2003.08. 004.

Roser, M., Ritchie, H., Ortiz-Ospina, E., \& Hasell, J. (2020). Coronavirus pandemic (COVID-19). https:// ourworldindata.org/coronavirus

Schumacher, Y.O., Tabben, M., Hassoun, K., et al. (2020). Resuming professional football during the Covid-19 pandemic in a country with high infection rates: a prospective cohort study. medRxiv. https://doi.org/10.1101/2020.11.17. 20233023.

Walsh, K. A., Jordan, K., Clyne, B., Rohde, D., Drummond, L., Byrne, P., Ahern, S., Carty, P. G., O'Brien, K. K., O'Murchu, E., O'Neill, M., Smith, S. M., Ryan, M., \& Harrington, P. (2020). SARS-CoV-2 detection, viral load and infectivity over the course of an infection. The Journal of Infection, 81(3), 357-371. https://doi.org/10.1016/j.jinf.2020.06. 067.

Williamson, E.J., Walker, A.J., Bhaskaran, K., et al. (2020). Factors associated with COVID-19related death using OpenSAFELY. Nature, 584, 430-436. https://doi.org/10.1038/s41586-0202521-4.

Wilson, M. G., Hull, J. H., Rogers, J., Pollock, N., Dodd, M., Haines, J., Harris, S., Loosemore, M., Malhotra, A., Pieles, G., Shah, A., Taylor, L., Vyas, A., Haddad, F. S., \& Sharma, S. (2020). Cardiorespiratory considerations for return-to-play in elite athletes after COVID-19 infection: a practical guide for sport and exercise medicine physicians. British Journal of Sports Medicine, 54(19), 1157-1161. https://doi.org/10.1136/bjsports-2020-102710.

Winichakoon, P., Chaiwarith, R., Liwsrisakun, C., Salee, P., Goonna, A., Limsukon, A., \& Kaewpoowat, Q. (2020). Negative nasopharyngeal and oropharyngeal swabs do not rule out COVID-19. Journal of Clinical Microbiology, 58(5), e0029720. https://doi.org/10.1128/JCM.00297-20.

Wölfel, R., Corman, V.M., Guggemos, W., Seilmaier M., Zange, S., Müller, M.A., Niemeyer, D., Jones, T. C., Vollmar, P., Rothe, C., Hoelscher, M., Bleicker, T., Brünink, S., Schneider, J., Ehmann, R., Zwirglmaier, K., Drosten, C., \& Wendtner, C. (2020). Virological assessment of hospitalized patients with COVID-2019. Nature, 581(7809), 465-469. https://doi.org/10.1038/s41586-0202196-x.

World Health Organization (2020). Directorgeneral's opening remarks at the media briefing on COVID-19. https://www.who. int/director-general/speeches/detail/whodirector-general-s-opening-remarks-at-themedia-briefing-on-covid-19---11-march-2020

World Health Organization Novel Coronavirus (2019-nCoV) technical guidance. Laboratory 62: testing for 2019-nCoV in humans. https://www.who.int/emergencies/ diseases/novel-coronavirus-632019/technicalguidance/laboratory-guidance
Yan, Y., Chang, L., \& Wang, L. (2020). Laboratory testing of SARS-CoV, MERS-CoV, and SARS-CoV-2 (2019-nCoV): current status, challenges, and countermeasures. Reviews in Medical Virology, 30(3), e2106. https://doi.org/10.1002/rmv.2106. 